up and a plaster dressing was adapted. There was neither pain nor spasm during convalescence. Everything was taken off on October 19.

For several months the temperature of the limb was lowered. It had a dusky hue, its nutrition and innervation being seriously impaired. The complete division of the anterior blood-vessels and nerves left everything to be done by the posterior group. When first seen, mortification seemed imminent. The operation had two things in view :

r. To prevent gangrene and save the limb by inducing prompt union throughout; the idea being to remove bone which occupied the gap, and which, being the focus of inflammation and suppuration, threatened the posterior blood and nerve supply. 2 . Or to anticipate a probable long siege of periostitis, ostitis, necrosis or osteo-myelitis.

The accompanying cut shows the patient thirteen months after the injury. Both heels are on the floor, which gives a clear conception of the postural defornity. The following measurements are further explanatory of the result:

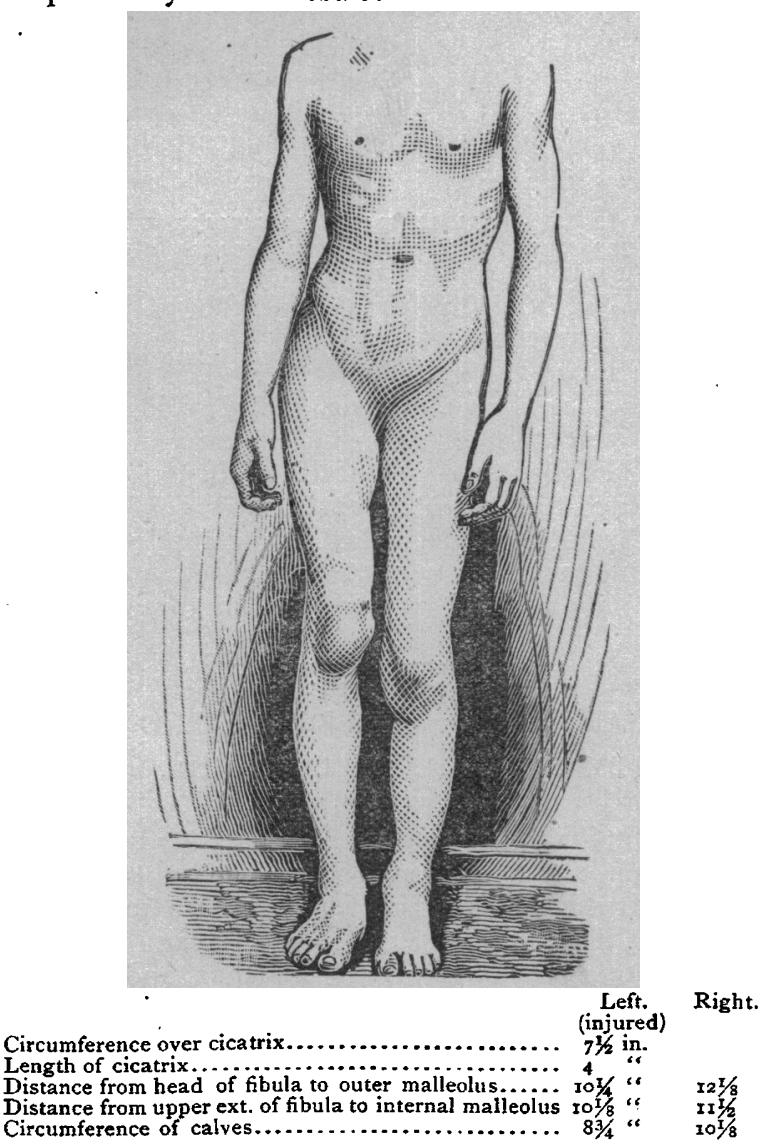

Dr. Martel is to be congratulated on his good result. His operation was a secondary procedure; this was primary. It would not pay to try to generalize with these three cases for a text. They may be sufficient to raise a question, however, as to the propriety of exsection in certain bad cases of compound fracture.

No. 126 E. Long St., Columbus, O., Sept. 9, 1886.

\section{LAPAROTOMY FOR REMOVAL OF MONOCYST OF OVARY. ${ }^{1}$}

BY T. W. HURLEY, M.D.,

OF BRNTONVILLE, ARK.

I saw for the first time, and examined Mrs. $H$. in consultation with Dr. Hartly Weems, of Rogers, in October, 1885 .

Patient æt. 36 , married nineteen years; no children, no abortions; physical condition fairly good; has had an abdominal tumor for very nearly two years. No cachexia. A tumor of considerable size was felt in the abdomen, reaching about six inches above the pubis, and mainly in left side. Bimanual exploration gave but little pain.

The character of the tumor was explained to the patient, and she was told that nothing short of an operation would afford any permanent relief. As the disease progressed it became more and more painful, and we were frequently importuned to operate. A puncture was spoken of, but the patient, on being told that the procedure would in all probability be only palliative, insisted on a radical operation. An operation was determined on and the patient put on preparatory treatment, mainly tonic and hygienic. Drs. Welch and Gray, of Fayetteville, were requested to meet us in consultation on January $18,1886$. After careful examination and consultation an operation-ovariotomy-was concurred in, and Io A.M. the next day the time for the operation.

Ten o'clock A.M., January 19. The patient, seeming cheerful and in good condition, was placed upon the table, and Drs. Gray and Weems administered a mixture of chloroform and ether. The patient was one of the most difficult to bring under its influence, requiring an hour and fifteen minutes to properly anæsthetize her.

Assisted by Dr. Welch, abdominal section in the median line was made, and a large monocyst which had developed from the left ovary was exposed. The cyst was partially evacuated, drawn out as nearly as possible and cut off. There was no pedicle, and very little adhesion. The intra-abdominal wound was well constricted by silk suture with several threads, and left in the abdomen. The external wound was closed and dressed antiseptically. The toilet being completed, the patient was carefully taken from the table and placed upon the bed. The patient, at this time having returned to consciousness, did not seem to be in an unfavorable condition; but in about half an hour was observed by Dr. Welch to be in an alarming state-extreme pallor, cold surface, frequent pulse, and feeble respiration. In addition she showed a marked and unceasing restlessness, to which succeeded vomiting and painful eructations. These symptoms, with but one short respite-when the temperature rose to about $100^{\circ}$, and soon falling below $96^{\circ}$-presaging a fatal issue, which finally occurred from total collapse at 8 o'clock P.M. the 2oth, about thirty hours from completion of the operation.

I think I may say now that the difficulties and

1 Rea d before the State Medical Society of Arkansas, Eleventh Annual Session, April 28, 1886 . 
dangers in this case were largely due to the very extensive origin of the growth, there being no welldefined pedicle, and consequently a very extensive ligation of tissue. It is true that this should not ordinarily produce a disastrous result, and I have the report of a case in which a rapidly growing ovarian tumor-only having been noticed by the patient six weeks-in which the operation was prolonged from numerous adhesions and the bursting of a cyst, the pedicle broad, which was ligated in sections with shoemaker's thread, and yet the patient did well. I think that the very profound and almost immediately fatal shock, together with bad toleration of the anæsthetics used, the effects of which persisted to the last, were the chief factors in the fatal termination of this case.

That an operation was justifiable there can be no doubt, as the patient repeatedly solicited it, and no other procedure could have with any certainty given a hope of prolonged life. And I may say the above opinions are fully concurred in by Drs. Welch and Gray, to whom Dr. Weems and myself are under many obligations for the valuable assistance rendered in the case.

\section{PERMANGANATE OF POTASH IN THE TREATMENT OF ECZEMA. ${ }^{1}$}

BY W. B. LAWRENCE, M.D., OF BATESVille, ARK.

In the Medical and Surgical Reporter, of July x I, $\mathbf{8 8 5}$, I read the following in regard to "Permanganate Potash Baths:"

"In June, I879, a well-developed child, of two years of age, was brought to Dr. Hüllman (Archiv. für Kinderheilk, Band vi, Heft 3), covered with eczema and impetigo. He had been sent from Berlin to Halle to try the baths there, but after three weeks he was worse instead of better. He was therefore prescribed an immersion-bath of permanganate of potash of the strength of fifteen grains to a pail of water, the child to remain in it until the fluid began to turn brownish. Fourteen days afterwards he was cured. Since then Dr. Hüllman has used the remedy both in adults and in children, and mostly with good effect. He has not confined its use to eczema, but has also employed it in prurigo, intertrigo, and the desquamating stage of measles, scarlatina and varicella. When the skin is much covered with scales or scabs it should first be well brushed with soap and water. For convenience of use he keeps a concentrated solution made of hot water."

At the time I saw this short article I had under treatment a very stubborn case of chronic eczema. I say chronic, because it was of almost three months' duration. It covered nearly the entire surface of all the fingers on one hand. The patient, a married lady, and in perfect health otherwise, had a hereditary predisposition to eczema. I had about exhausted all of the remedies generally used in this disease, so far as my knowledge goes. I had prescribed

1 Read before the State Medical Society of Arkansas, Eleventh Annual Session, Little Rock, April 28 and $29,1886$. the tar ointment, citrine ointment, and others, besides nitric acid, with which I have cured similar cases heretofore; and in addition to the local remedies the patient had been taking liq. pot. arsenitis, 6 to 8 drops after each meal.

Under this treatment my patient's malady did not improve in the least, but gradually grew worse. Anxious to try anything reasonable, and remembering the good effects claimed for this drug in the treatment of some forms of foul ulcers, I ordered the following:

R. Potassii permanganas............... grs. $x$

Aquæ.................................

The solution to be applied freely daily with a camel's-hair brush. Under this treatment the disease entirely disappeared in about twelve days. Of course the new skin remained somewhat tender for some days. She left off the arsenic when she began the potash.

I think it was in September that I treated another case of eczema. The patient was a young lady, and in other respects her health was perfect; no hereditary tendency, so far as I was able to find out, of any form of skin disease. The disease was on the face, in the region of the mouth, in fact almost covering both lips. She had used iodine and carbolized cosmoline, but with no good effect. I ordered

$$
\text { Pot. permangs.................... grs. } \mathbf{v}
$$$$
\text { Aquæ..................................... }
$$

The solution to be applied freely daily with a camel'shair brush. Under this treatment the patient was cured within fifteen days.

In December I saw another case. The patient, a child one year of age, a male, well developed, and with the exception of this skin disease in perfect health. The disease was situated in the external ear and extended to some little extent down on the jaw. I ordered same formula as last, to be applied in the same manner as in the two previous cases, and within a week's time the disease had entirely disappeared.

\section{NARCEINE IN WHOOPING-COUGH.' BY LLEWELLYN ELIOT, M.D., OF WASHINGTON, D, $\mathrm{C}$.}

Whooping-cough is one of the most distressing diseases of childhood, although it has been observed in adults. It seldom occurs before the sixth month of life, nor is it frequent after the eighth year. Second attacks are exceedingly rare. Barthez and Rilliet mention a case occurring on the day after birth, the mother having had the disease four weeks previously. Bouchet mentions a case infected on the second day of life, developing on the eighth. Keating records a case of a child born with the disease. Steiner has seen it between the second and third weeks.

The pathology of the disease is unsettled, but it appears to be a catarrh of the respiratory organs, combined with an affection of the respiratory nerves, rather than a pure neurosis. This unsettled pathology has led to the employment of remedies without

1 Read before the Medical Society of the District of Columbia, December 8,5886 . 